\title{
Leukocyte- and platelet-rich fibrin as an adjuvant to the surgical approach for osteoradionecrosis: a case report
}

\author{
Gustavo Maluf ${ }^{1}$, Rogério Jardim Caldas', Eduardo Rodrigues Fregnani², Paulo Sérgio da Silva Santos ${ }^{1}$ \\ ${ }^{1}$ Department of Surgery, Stomatology, Pathology and Radiology, Bauru School of Dentistry, University of São Paulo, Bauru, \\ ${ }^{2}$ Departament of Oral Medicine, Hospital Sírio-Libanês, São Paulo, Brazil
}

\begin{abstract}
J Korean Assoc Oral Maxillofac Surg 2020;46:150-154)
We present a case of osteoradionecrosis treated with leukocyte- and platelet-rich fibrin (LPRF) and surgery and followed up with clinical and tomographic investigations. A 65-year-old woman presented with pain in the posterior region of the right palate. Her medical history included cardiovascular disease and squamous cell carcinoma in the anterior region of the floor of the mouth that had been treated with intensity-modulated radiation therapy. Measurements of isodose curves showed a full dosage of 6,462.6 cGy in the anterior mandibular region, whereas that in the posterior region on the right side of the maxilla reached 5,708.1 cGy. Osteotomy was performed using rotary instruments, and debridement and placement of two LPRF membranes were also carried out. New gum tissue with no bone exposure was noted 14 days postoperatively. Tissue repair was complete, and the patient had no further complaints. During a 39-month follow-up period, the oral mucosa remained intact, and the patient was rehabilitated with a new upper denture. Since there is no consensus regarding the best protocol to treat osteoradionecrosis, LPRF might be an interesting adjuvant to a surgical approach. The use of LPRF is simple and reduces operational costs, time of handling, probability of technical failure, and associated morbidities for patients with osteoradionecrosis.
\end{abstract}

Key words: Osteoradionecrosis, Oral surgery, Cone-beam computed tomography

[paper submitted 2018. 4. 24 / revised 2018. 7. 3 / accepted 2018. 7. 4]

\section{Introduction}

Osteoradionecrosis (ORN) is defined as an area of exposed bone that persists for more than three months ${ }^{1}$. It is a diagnosis of exclusion and affects $2 \%$ to $15 \%$ of patients undergoing radiotherapy of the head and neck ${ }^{2}$. However, ORN may only be evident in radiographic images if no clinical manifestations are present, such as disruption in the oral mucosa or cervicofacial $\mathrm{skin}^{3}$. Mandibular ORN is more prevalent than maxillary ORN because the mandibular bone is dense but weakly vascular².

\section{Gustavo Maluf}

Department of Surgery, Stomatology, Pathology and Radiology, Bauru School of Dentistry, University of São Paulo, Al. Dr. Octávio Pinheiro Brisolla, 9-75, Bauru 17012-901, Brazil

TEL: +55-14-3235-8000 FAX: +55-14-3226-6113

E-mail: gustavomaluf@usp.br

ORCID: https://orcid.org/0000-0001-5507-1824

(c) This is an open-access article distributed under the terms of the Creative Commons Attribution Non-Commercial License (http://creativecommons.org/ licenses/by-nc/4.0/), which permits unrestricted non-commercial use, distribution, and reproduction in any medium, provided the original work is properly cited.

Copyright (C) 2020 The Korean Association of Oral and Maxillofacial Surgeons. All rights reserved.
Marx ${ }^{4}$ described ORN as a conjunction of hypoxia, hypocellularity, and hypovascularization and proposed that the condition be managed with surgery and hyperbaric oxygen (HBO) treatment. Research has been performed on HBO and many other modalities of treatment, including antiseptic mouthwashes, antibiotics, sequestrectomy, ultrasound therapy, biological molecules, and surgical treatments (including those that involve microvascular reconstruction) ${ }^{5}$. Intensitymodulated radiation therapy (IMRT) is a radiotherapy technique used to deliver precise doses of radiation to a malignant tumor or specific areas within a tumor and thereby minimizes the amount delivered to surrounding normal tissue. As a result, IMRT decreases the incidence and severity of ORN more than other conventional radiotherapy techniques ${ }^{5}$.

Platelet-rich plasma (PRP) promotes coagulation. Platelets are a rich source of important growth factors (platelet-derived growth factor, transforming growth factors beta 1 and 2, and vascular endothelial growth factors) involved in the angiogenic cascade and in the healing of both soft and hard tissues $^{6}$. Scala et al. ${ }^{7}$ reported the first case of ORN to be treated with autologous platelet concentrates. The necrotic bone was 
removed, and PRP was used for primary closure of the mucosa. No injuries were noted during the two-year follow-up period.

Leukocyte- and platelet-rich fibrin (LPRF) is a second-generation platelet concentrate (autologous natural fibrin matrix) that accelerates angiogenesis and multiplication of fibroblasts and osteoblasts ${ }^{8}$. LPRF is an immunological platelet concentrate retained in a single membrane of fibrin that contains all the blood components favorable for healing and immunity'. When combined with a bone graft, LPRF accelerates bone healing. Histologically, bones form and mature in a shorter time with use of LPRF than with the aid of other techniques. The healing effects of LPRF on tissues are superior to those of PRP ${ }^{9}$.

Surgical treatment with LPRF has been used to manage medication-related osteonecrosis of the jaw with promising results ${ }^{10}$. Nonetheless, to the best of our knowledge, there have been no reports on use of LPRF in treatment of ORN. Therefore, we present a case in which LPRF and surgery were used to treat ORN and for which there were both clinical and tomographic follow-up data available. Patient consent was obtained for publication of these case details.

\section{Case Report}

A 65-year-old woman presented with pain in the posterior region of the right palate. Her medical history included cardiovascular disease (subepicardial ischemia) and squamous cell carcinoma, for which she was treated with IMRT in the

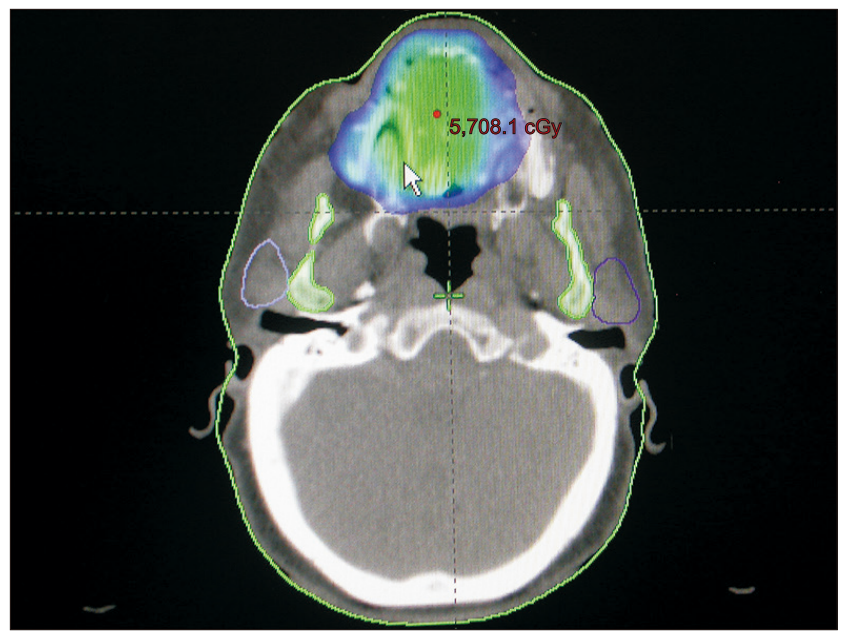

Fig. 1. Radiation dosage distribution map of the osteoradionecrosis area.

Gustavo Maluf et al: Leukocyte- and platelet-rich fibrin as an adjuvant to the surgical approach for osteoradionecrosis: a case report. J Korean Assoc Oral Maxillofac Surg 2020 anterior region of the floor of the mouth. Measurements of isodose curves showed a full dosage of 6,462.6 cGy in the anterior mandibular region. In the posterior region on the right side of the maxilla, the dosage reached 5,708.1 cGy. (Fig. 1) The patient was taking $500 \mathrm{mg}$ acetylsalicylic acid (AAS; Sanofi Aventis, Gentilly, France) and 75 mg clopidogrel (Plavix; Sanofi Aventis). A section of approximately $12 \mathrm{~mm}$ of exposed bone was visible, and purulent secretion draining from the posterior alveolar ridge on the right side of the maxilla was accompanied by pain in that area. The patient wore an upper denture.(Fig. 2) Thus, the condition was diagnosed as Stage III ORN ${ }^{2}$. Cone-beam computed tomography (CBCT) findings included osteolysis of the posterior alveolar ridge on the right side of the maxilla and the maxillary sinus floor with bone sequestrum and complete opacification caused by ORN.(Fig. 3) The leukocyte count was 6,400 cells/ $\mu \mathrm{L}(4,160$ segmented neutrophils/ $\mu \mathrm{L} ; 0$ band neutrophils $/ \mu \mathrm{L})$. The hemoglobin level was $10.4 \mathrm{~g} / \mathrm{dL}$, and the platelet count was 351,000 cells $/ \mathrm{mm}^{3}$.

An osteotomy was performed using rotary instruments; the area was debrided, and two LPRF membranes were placed. We used the LPRF protocol developed in France by Choukroun et $\mathrm{al}^{8}$. The LPRF was obtained from a $20-\mathrm{mL}$ venous blood sample obtained from the patient before surgery.(Fig. 4) An antibiotic ( $875 \mathrm{mg}$ amoxicillin/clavulanic acid) and mouth rinsing regime $(0.2 \%$ chlorhexidine gluconate $)$ were prescribed daily for the next three weeks.

New gum tissue with no bone exposure was noted 14 days postoperatively. Thus, the tissue repair was complete, and the patient had no further complaints. During the 39-month

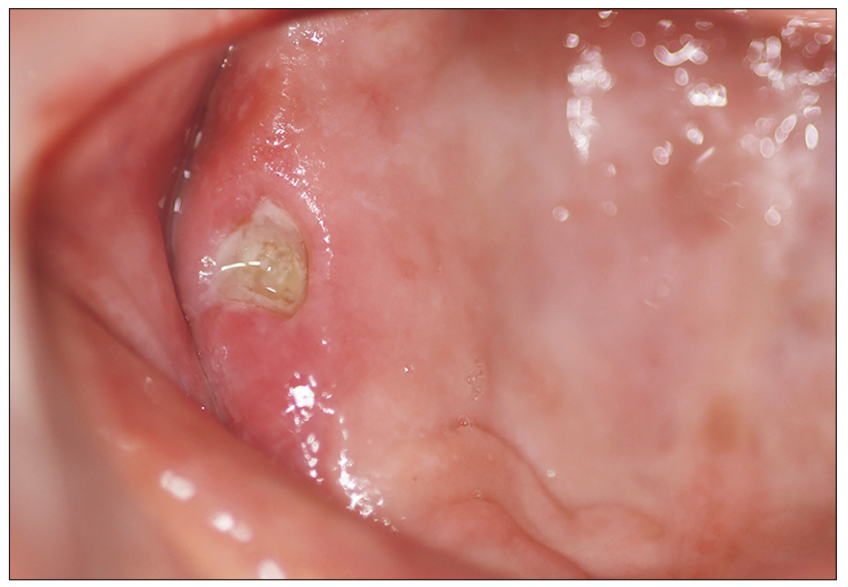

Fig. 2. Area of exposed bone in the maxilla with purulent drainage.

Gustavo Maluf et al: Leukocyte- and platelet-rich fibrin as an adjuvant to the surgical approach for osteoradionecrosis: a case report. J Korean Assoc Oral Maxillofac Surg 2020 


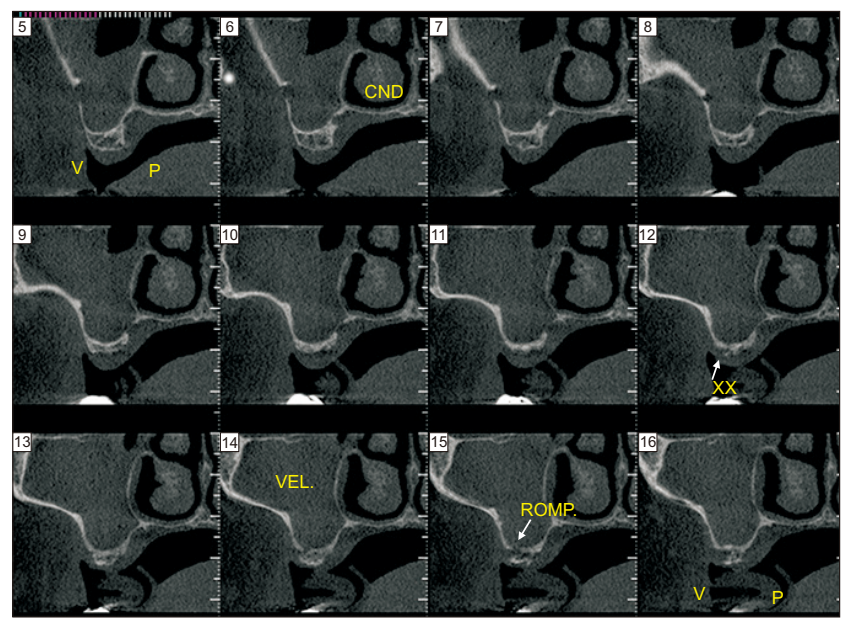

Fig. 3. Computed tomography findings: Sinusitis (complete opacification of maxillary sinus), sequestrum formation, cortical disruption, and osteolysis. (V: buccal, P: lingual, CND: right nasal cavity, $X X$ : osteolysis, VEL: opacification of maxillary sinus, ROMP: cortical disruption)

Gustavo Maluf et al: Leukocyte- and platelet-rich fibrin as an adjuvant to the surgical approach for osteoradionecrosis: a case report. J Korean Assoc Oral Maxillofac Surg 2020

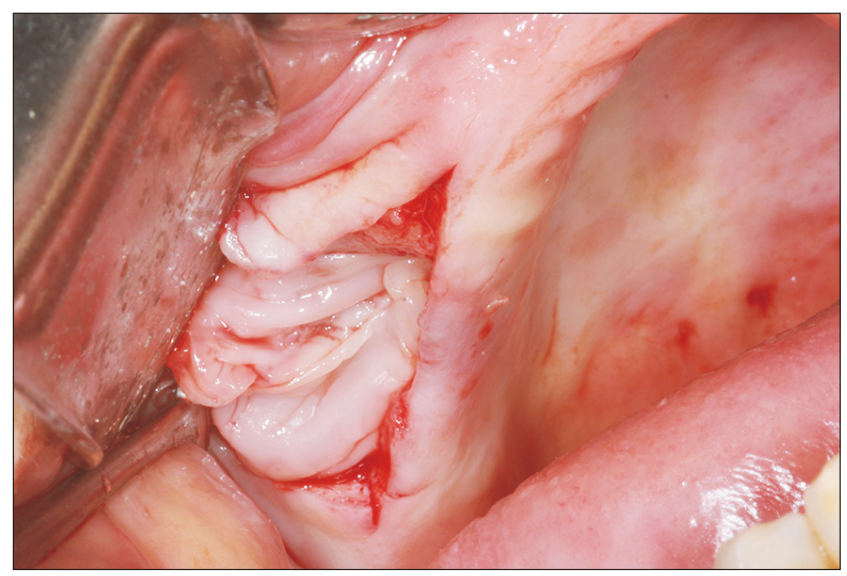

Fig. 4. Leukocyte- and platelet-rich fibrin placement in the surgical area.

Gustavo Maluf et al: Leukocyte- and platelet-rich fibrin as an adjuvant to the surgical approach for osteoradionecrosis: a case report. J Korean Assoc Oral Maxillofac Surg 2020

follow-up period, the oral mucosa remained intact, and the patient was rehabilitated with a new upper denture.(Fig. 5) Tomographic images obtained 36 months postoperatively showed that sequestra, sinusitis, and bone lysis were absent, although there was disruption of the cortical bone of the maxillary sinus caused by the osteotomy.(Fig. 6)

\section{Discussion}

ORN is a debilitating complication of radiation therapy, and the most effective measure against this condition is pre-

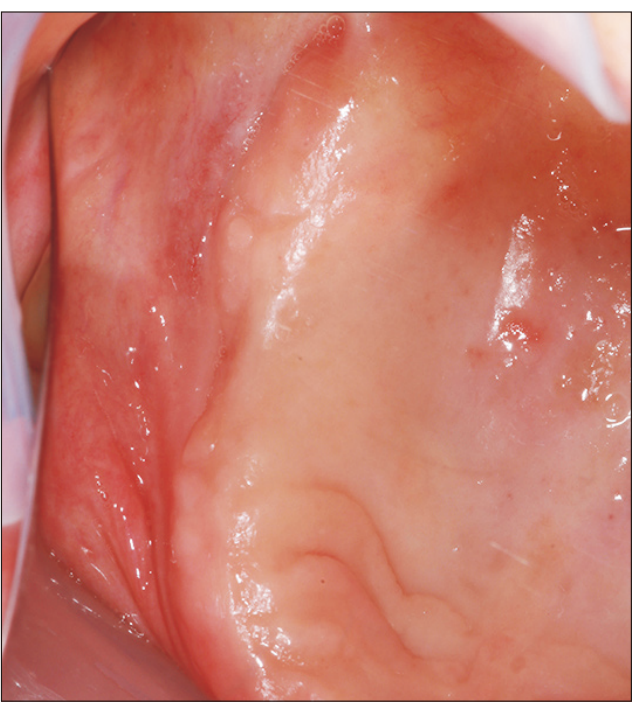

Fig. 5. Postoperative period of 39 months showing complete mucosal wound covering.

Gustavo Maluf et al: Leukocyte- and platelet-rich fibrin as an adjuvant to the surgical approach for osteoradionecrosis: a case report. J Korean Assoc Oral Maxillofac Surg 2020

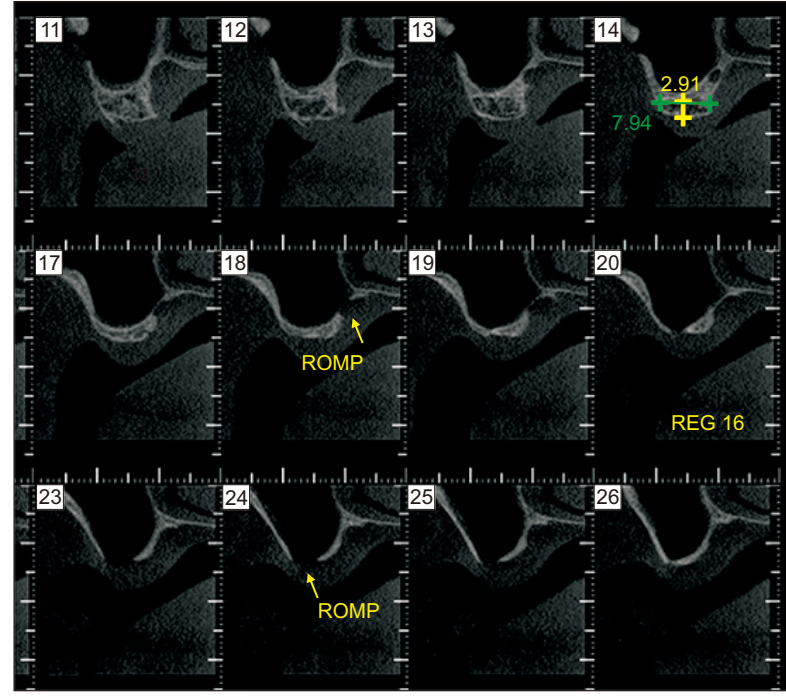

Fig. 6. Computed tomography findings: No signs of sinusitis sequestrum formation or osteolysis. It is shown the disruption of the cortical bone of the maxillary sinus caused by the osteotomy. (ROMP: cortical disruption, REG: regeneration)

Gustavo Maluf et al: Leukocyte- and platelet-rich fibrin as an adjuvant to the surgical approach for osteoradionecrosis: a case report. J Korean Assoc Oral Maxillofac Surg 2020

vention. Conservative management with antibiotics, local treatment, and $\mathrm{HBO}$ has been shown to be effective in $25 \%$ to $44 \%$ of cases $^{3,11}$. Maier et al. ${ }^{12}$ demonstrated that postoperative $\mathrm{HBO}$ was not effective in cases of severe ORN and is not a treatment choice in cases of surgical failure. Bessereau and Annane ${ }^{13}$ showed that HBO was ineffective as a sole treatment. In a meta-analysis, Bennett et al. ${ }^{14}$ confirmed that HBO 
might be useful as an adjuvant treatment, while Gal et al. ${ }^{15}$ observed that microvascular reconstruction without $\mathrm{HBO}$ was a successful approach to ORN management. Hence, there is no consistent evidence on which to base protocols for ORN treatment.

Oh et al. ${ }^{16}$ reported that $65 \%$ of patients who received more than $6,000 \mathrm{cGy}$ of radiation therapy had a poor response to conservative treatment for ORN. These results are in agreement with those found by Beumer et al. ${ }^{11}$, who concluded that patients with ORN who are exposed to dosages greater than 6,500 cGy do not respond favorably to conservative management. Because the dosage received in the tumor region (floor of mouth) of our patient was 6,462 cGy, and the one administered to the right palate posterior region was 5,708 cGy, the isodose curves indicated a likely favorable response to the proposed treatment. A dose distribution map can be used to determine the areas most affected by radiation and to correlate those areas with oral complications after radiotherapy ${ }^{17}$. A great deficiency is observed in the published reports on ORN because only the dose delivered to the tumor area is mentioned, and precise information about the region of necrosis is usually missing ${ }^{7,18}$. Thus, the amount of radiation delivered to the affected bone may determine the prognosis of treatment and indicate the importance of a dose distribution map.

Based on the current understanding of the pathophysiology of ORN, new therapeutics have been developed to inhibit the radiation-induced fibroatrophic process and have challenged the concept of treatment using hypoxia. A new regimen inhibits this process with use of drugs such as pentoxifylline, tocopherol, and clodronate, all of which can eliminate the need for surgery to treat initial lesions. Although advanced lesions may not be resolved with these drugs, the lesions might not progress $^{19}$. This therapy is based on retrospective data from case reports, but there are currently no prospective controlled studies to confirm its effectiveness.

Manimaran et al. ${ }^{18}$ presented two cases of mandibular ORN that were successfully treated with autologous bone marrow concentrate stem cells and allogeneic dental pulp stem cells with PRP after conventional methods failed. Both patients healed completely within a $24-$ month follow-up period. Despite the positive results, this method is expensive and not as clinically practical as use of LPRF.

Manimaran et al. ${ }^{18}$ successfully healed bones using stem cells and PRP, whereas Scala et al. ${ }^{7}$ achieved the same using only PRP. However, both research teams used panoramic radiography, an imprecise imaging method. In the present case report, $\mathrm{CBCT}$, which can show bone repair more accurately, was used. Nevertheless, no new bone formation was seen.

Unlike PRP, LPRF does not dissolve quickly after use; hence, the architecture of the fibrin matrix is preserved. LPRF, which incorporates a concentrate of platelet-rich leukocytes and fibrin, does not include additional chemicals and therefore allows coagulation to occur naturally. LPRF also has many other advantages over PRP. LPRF can be used as a barrier membrane and to store cells such as platelets. It contains seven times the quantity of growth factors than PRP but allows for slow release of these growth factors over 7 to 28 days. Because LPRF does not disintegrate as quickly as PRP, it can contribute to healing of the wound (especially soft tissue) for a longer period of time. In addition, LPRF has a longer shelf life than PRP. Leukocyte and platelet concentrates function as anti-infective agents and immune system regulators ${ }^{9}$. ORN is characterized by bone exposure and decreases in vascularization ${ }^{4}$; LPRF can yield better results than PRP because it has angiogenic and anti-infective properties and provides a protective barrier to the oral environment.

Dohan Ehrenfest et al. ${ }^{20}$ aimed to create an overview of the systems available and to categorize them according to fibrin density, leukocyte content, and degree of standardization of the procedure. The classification system described by Dohan Ehrenfest et al. ${ }^{20}$ consists of categories of leukocyte-poor or pure PRP, leukocyte- and pure-rich plasma, leukocyte-poor or leukocyte-rich pure fibrin platelets, and LPRF. The literature on platelet concentrates often ignores the effects of numbers of white blood cells and fibrin, which are two key parameters for classification. Many authors use the term, "platelet-rich fibrin"; however, according to Dohan Ehrenfest et al. ${ }^{20}$, the more appropriate term would be LPRF, which reflects the importance of the leukocytes in the concentrates.

Surgical approaches, such as sequestrum removal and debridement of superficial bones, have been described in previous studies as conservative treatments, but these treatments are effective only for the initial stages of $\mathrm{ORN}^{5,16}$. For advanced-stage ORN, conservative surgery with LPRF has shown promising results, such as those seen in this case, and can reduce the need for extensive surgical resections. No signs of sinusitis were observed six months after the surgery in the present report. LPRF was used as an adjunct to the surgical approach. This membrane created a physical barrier, leading to the sealing of the maxillary sinus with only minor trauma. Despite the pedicle buccal fat pad graft as a therapeutic option for oro-antral communication, this modality would have caused a greater morbidity to our patient. In addition, 
LPRF can control local infection, regulate the immunologic response ${ }^{9}$, and accelerate tissue repair.

The use of LPRF is simple and reduces surgical costs, handling time, probability of technical failure, and morbidities in patients with ORN. In cases of focal osteonecrosis of the jaw, LPRF can contribute to wound healing and decrease the risk of morbidities.

\section{ORCID}

Gustavo Maluf, https://orcid.org/0000-0001-5507-1824

Rogério Jardim Caldas, https://orcid.org/0000-0001-6410-0551

Eduardo Rodrigues Fregnani, https://orcid.org/0000-0001-5196-7631

Paulo Sérgio da Silva Santos, https://orcid.org/0000-0002-0674-3759

\section{Authors' Contributions}

G.M. performed the data collection, surgery, and writing of the article. R.J.C. contributed writing. E.R.F. performed a review of the article. P.S.S.S. performed a review of the article and orientation of the study.

\section{Conflict of Interest}

No potential conflict of interest relevant to this article was reported.

\section{References}

1. Harris M. The conservative management of osteoradionecrosis of the mandible with ultrasound therapy. Br J Oral Maxillofac Surg 1992;30:313-8

2. Epstein JB, Wong FL, Stevenson-Moore P. Osteoradionecrosis: clinical experience and a proposal for classification. J Oral Maxillofac Surg 1987;45:104-10.

3. Lyons A, Osher J, Warner E, Kumar R, Brennan PA. Osteoradionecrosis: a review of current concepts in defining the extent of the disease and a new classification proposal. Br J Oral Maxillofac Surg 2014;52:392-5.

4. Marx RE. Osteoradionecrosis: a new concept of its pathophysiology. J Oral Maxillofac Surg 1983;41:283-8.

5. Rice N, Polyzois I, Ekanayake K, Omer O, Stassen LF. The management of osteoradionecrosis of the jaws: a review. Surgeon 2015;13:101-9.

6. Roukis TS, Zgonis T, Tiernan B. Autologous platelet-rich plasma for wound and osseous healing: a review of the literature and commercially available products. Adv Ther 2006;23:218-37.

7. Scala M, Gipponi M, Mereu P, Strada P, Corvò R, Muraglia A, et al. Regeneration of mandibular osteoradionecrosis defect with platelet rich plasma gel. In Vivo 2010;24:889-93.

8. Choukroun J, Adda F, Schoeffer C, Vervelle A. PRF: an opportunity in perio-implantology. Implantodontie 2001;42:55-62. French.

9. Choukroun J, Diss A, Simonpieri A, Girard MO, Schoeffler C, Dohan SL, et al. Platelet-rich fibrin (PRF): a second-generation platelet concentrate. Part IV: clinical effects on tissue healing. Oral Surg Oral Med Oral Pathol Oral Radiol Endod 2006;101:e56-60.

10. Maluf G, Caldas RJ, Silva Santos PS. Use of leukocyte- and platelet-rich fibrin in the treatment of medication-related osteonecrosis of the jaws. J Oral Maxillofac Surg 2018;76:88-96.

11. Beumer J, Harrison R, Sanders B, Kurrasch M. Osteoradionecrosis: predisposing factors and outcomes of therapy. Head Neck Surg 1984;6:819-27.

12. Maier A, Gaggl A, Klemen H, Santler G, Anegg U, Fell B, et al. Review of severe osteoradionecrosis treated by surgery alone or surgery with postoperative hyperbaric oxygenation. Br J Oral Maxillofac Surg 2000;38:173-6.

13. Bessereau J, Annane D. Treatment of osteoradionecrosis of the jaw: the case against the use of hyperbaric oxygen. J Oral Maxillofac Surg 2010;68:1907-10.

14. Bennett MH, Feldmeier J, Hampson NB, Smee R, Milross C. Hyperbaric oxygen therapy for late radiation tissue injury. Cochrane Database Syst Rev 2016;4:CD005005.

15. Gal TJ, Yueh B, Futran ND. Influence of prior hyperbaric oxygen therapy in complications following microvascular reconstruction for advanced osteoradionecrosis. Arch Otolaryngol Head Neck Surg 2003;129:72-6.

16. Oh HK, Chambers MS, Martin JW, Lim HJ, Park HJ. Osteoradionecrosis of the mandible: treatment outcomes and factors influencing the progress of osteoradionecrosis. J Oral Maxillofac Surg 2009;67:1378-86.

17. Parahyba CJ, Ynoe Moraes F, Ramos PA, Haddad CM, da Silva JL, Fregnani ER. Radiation dose distribution in the teeth, maxilla, and mandible of patients with oropharyngeal and nasopharyngeal tumors who were treated with intensity-modulated radiotherapy. Head Neck 2016;38:1621-7.

18. Manimaran K, Sankaranarayanan S, Ravi VR, Elangovan S, Chandramohan M, Perumal SM. Treatment of osteoradionecrosis of mandible with bone marrow concentrate and with dental pulp stem cells. Ann Maxillofac Surg 2014;4:189-92.

19. Delanian S, Chatel C, Porcher R, Depondt J, Lefaix JL. Complete restoration of refractory mandibular osteoradionecrosis by prolonged treatment with a pentoxifylline-tocopherol-clodronate combination (PENTOCLO): a phase II trial. Int J Radiat Oncol Biol Phys 2011;80:832-9.

20. Dohan Ehrenfest DM, Rasmusson L, Albrektsson T. Classification of platelet concentrates: from pure platelet-rich plasma (P-PRP) to leucocyte- and platelet-rich fibrin (L-PRF). Trends Biotechnol 2009;27:158-67.

How to cite this article: Maluf G, Caldas RJ, Fregnani ER, da Silva Santos PS. Leukocyte- and platelet-rich fibrin as an adjuvant to the surgical approach for osteoradionecrosis: a case report. J Korean Assoc Oral Maxillofac Surg 2020;46:150-154. https://doi. org/10.5125/jkaoms.2020.46.2.150 